\title{
FONTES E PERÍODOS DE CONTATO DE FERTILIZANTES E GERMINAÇÃO DE SEMENTES DE Brachiaria brizantha ${ }^{(1)}$
}

\author{
Gustavo Pavan Mateus ${ }^{(2)}$, Émerson Borghi ${ }^{(3)}$, Rúbia Renata Marques $^{(3)}$, \\ Roberto Lyra Villas Bôas ${ }^{(4,6)}$ \& Carlos Alexandre Costa Crusciol ${ }^{(5,6)}$
}

\begin{abstract}
RESUMO
A mistura de sementes forrageiras com fertilizantes pode viabilizar o cultivo consorciado, por diminuir a competição com a cultura produtora de grãos. No entanto, se realizada muito antes da semeadura, pode prejudicar a emergência e o estabelecimento das forrageiras. Realizou-se trabalho em condições de laboratório e casa de vegetação, em Botucatu (SP), com o objetivo de avaliar a germinação de sementes de Brachiaria brizantha em razão do tempo de mistura com fertilizantes químicos. $O$ delineamento experimental empregado foi o inteiramente casualizado, com quatro repetições. Os tratamentos constaram de um fatorial 6 x 8, constituído de diferentes períodos de contato das sementes de Brachiaria brizantha cultivar Marandu (0, 6, 12, 24, 48 e 96 h) com os fertilizantes uréia, sulfato de amônio, cloreto de potássio, sulfato de potássio, superfosfato simples, superfosfato triplo e formulado N-P-K (8-28-16) nas formas de mistura de grânulos e farelado. Não houve relação entre os testes de germinação em laboratório e a emergência a campo. No solo, a emergência das plântulas de Brachiaria brizantha não é afetada se realizada a mistura com fertilizantes minerais fosfatados, cloreto de potássio e formulado farelado até $96 \mathrm{~h}$ antes da semeadura.
\end{abstract}

Termos de indexação: forrageira, adubos, emergência.

\footnotetext{
(1) Recebido para publicação em junho de 2005 e aprovado em dezembro de 2006.

(2) Pesquisador Científico do Pólo Regional de Desenvolvimento Tecnológico dos Agronegócios do Extremo Oeste - APTA, Caixa Postal 67, CEP 16900-000 Andradina (SP), E-mail: gpmateus@aptaregional.sp.gov.br

${ }^{(3)}$ Doutorando do Departamento de Produção Vegetal - Agricultura, Faculdade de Ciências Agronômicas, Universidade Estadual Paulista - FCA/UNESP. Caixa Postal 237, CEP 18603-970 Botucatu (SP). E-mail: borghi@fca.unesp.br

(4) Professor do Departamento de Recursos Naturais, FCA/UNESP. E-mail: rlvboas@fca.unesp.br

(5) Professor do Departamento de Produção Vegetal - Agricultura, FCA/UNESP. E-mail: crusciol@fca.unesp.br

(6) Bolsista CNPq.
} 


\title{
SUMMARY: SOURCES AND TIME OF CONTACT OF MINERAL FERTILIZER WITH Brachiaria brizantha SEEDS AS RELATED WITH GERMINATION
}

\begin{abstract}
The mixture of forage seeds with mineral fertilizers can make intercropping systems possible by reducing competition with the grain-producing crop. However, if the mixture is prepared too early before sowing, the emergence and establishment of the forages can be negatively affected. Therefore, experiment were carried out in laboratory and greenhouse conditions, in Botucatu, São Paulo, to evaluate Brachiaria brizantha seed germination as related to the time of contact with distinct chemical fertilizers. The experiment had a completely randomized block design, in a $6 \times 8$ factorial scheme, with six contact periods of Brachiaria brizantha $c v$. Marandu seeds $(0,6,12,24,48$, and 96 hours), with eight chemical fertilizers (urea, ammonium sulphate, potassium chloride, potassium sulphate, simple superphosphate, triple superphosphate, NPK 8-28-16 mixture as a mixture of granules or powder), in four replications. There was no relation between the germination tests under laboratory with that under field conditions. Under field conditions, Brachiaria brizantha plant emergence is not affected if the phosphate fertilizers, potassium chloride and formulated NPK powder are mixed with the seeds up to $96 \mathrm{~h}$ before sowing.
\end{abstract}

Index terms: Forage, mineral fertilizer, field emergence.

\section{INTRODUÇÃO}

Em algumas regiões produtoras do Brasil, o cultivo de apenas uma safra por ano agrícola inviabiliza o sistema plantio direto, em virtude da baixa produção e persistência das espécies destinadas à formação de cobertura morta. Assim, a adoção de sistemas integrados, como o cultivo consorciado de grãos com forrageiras tropicais, proporciona a viabilidade do sistema plantio direto, pela grande produção de massa vegetal e também pelo fornecimento de forragem no período de outono-inverno (Salton et al., 2001; Aidar et al., 2003; Jakelaitis et al., 2004). Esse sistema de produção vem sendo aplicado com grande sucesso em grande parte do Brasil, utilizando, principalmente, as forrageiras dos gêneros Brachiaria, Panicum e Andropogon (Kluthcouski et al., 2003).

A forrageira, nesse sistema, pode ser semeada simultaneamente na linha de semeadura da cultura produtora de grãos. Para isso, as sementes são misturadas ao adubo químico de semeadura da cultura produtora de grãos e depositadas no compartimento de fertilizante da semeadora, sendo distribuídas na mesma profundidade do adubo (Kluthcouski et al., 2000). Assim, o mesmo adubo usado na cultura produtora de grãos será utilizado pela forrageira, que, dependendo da cultura anual, apresentará desenvolvimento lento até a colheita de grãos (Portes et al., 2000). Somente após a colheita, a Brachiaria iniciará seu pleno desenvolvimento e se beneficiará do adubo residual deixado pela cultura anual. Uma outra forma de implantação desse sistema é a semeadura da forrageira no momento da aplicação do fertilizante de cobertura, ambos misturados, podendo ser até com formulados.
A técnica de implantação de forrageiras por meio da mistura de sementes com fertilizantes é uma prática antiga, muito empregada na implantação de pastagens, com o uso, principalmente, de fertilizantes fosfatados, visando à utilização do adubo como via de distribuição (Bacchi, 1974; Roston \& Kuhn Neto, 1978). No entanto, recomenda-se, nas misturas com adubos fosfatados, que a semeadura seja imediata, evitando danos na qualidade fisiológica das sementes (São Paulo, 1973; Moura, 1984). O prolongado período de contato do fertilizante com as sementes pode trazer prejuízos à germinação e ao vigor, dependendo do tipo de adubo fosfatado utilizado (Cavariani et al., 1994). Vários autores também referiram a possibilidade de ocorrência dos efeitos depressivos às sementes devido ao período de contato com os fertilizantes (São Paulo, 1973; Bacchi, 1974; Moura, 1984; Sader et al., 1991; Lima et al., 2000; Soratto et al., 2003).

Apesar da comprovada viabilidade técnica e econômica do consórcio entre milho e braquiária (Portes et al., 2000; Silva et al., 2004; Jakelaitis et al., 2004), o estabelecimento da forrageira com uma cultura consorciada ocorre sob condições de competição entre as espécies, principalmente na semeadura simultânea. Além disso, a inexistência de referências na literatura, no tocante ao cultivo consorciado, em especial ao tempo de mistura das sementes das forrageiras com os mais diversos fertilizantes minerais, pode estar comprometendo o sucesso do sistema, em razão de recomendações equivocadas, sem adequado embasamento científico.

O presente trabalho teve por objetivo avaliar a germinação de sementes de Brachiaria brizantha Stapf. cv. Marandu em condições de laboratório e em solo em casa de vegetação, em razão do tempo de mistura com fertilizantes minerais. 


\section{MATERIAL E MÉTODOS}

O trabalho foi realizado em abril de 2004, em condições de laboratório e em solo em casa de vegetação, em Botucatu (SP). O delineamento experimental empregado foi o inteiramente casualizado, com quatro repetições. Os tratamentos constaram de um fatorial $6 \times 8$, constituído de diferentes períodos de contato das sementes de Brachiaria brizantha cultivar Marandu $(0,6,12,24,48$ e $96 \mathrm{~h})$ com os fertilizantes uréia, sulfato de amônio, cloreto de potássio, sulfato de potássio, superfosfato simples - SFS, superfosfato triplo - SFT e formulado N-P-K (8-28-16) nas formas de mistura de grânulos e farelado, cujos atributos químicos e físicos foram previamente determinados (Quadros 1 e 2).

Antes da aplicação dos tratamentos, foram separadas 50 sementes de braquiária para cada repetição, acondicionando-as em sacos de papel, para as avaliações tanto em laboratório quanto em casa de vegetação. Adotou-se a proporção da mistura de $1 \mathrm{~g}$ de sementes de braquiária para cada $20 \mathrm{~g}$ de fertilizante (simulando uma condição prática, seria de $10 \mathrm{~kg}$ de sementes para $200 \mathrm{~kg} \mathrm{ha}^{-1}$ de fertilizante); previamente, retirou-se uma amostra de sementes, correspondente ao tratamento-testemunha. As sementes foram misturadas homogeneamente aos fertilizantes e mantidas sob condições de ambiente do laboratório, com temperatura variando entre 25 e $28^{\circ} \mathrm{C}$ e umidade relativa entre 45 e $65 \%$.

No laboratório, decorrido cada um dos períodos de contato preestabelecidos, separaram-se as sementes dos fertilizantes mediante o emprego de peneiras e pincéis, sendo elas submetidas à germinação sob temperatura constante de $25^{\circ} \mathrm{C}$, sem luz. Sobre papel-toalha foram dispostas 50 sementes por repetição, sendo posteriormente colocadas em caixa plástica (gerbox) para avaliações aos sete dias e final, aos 21 dias, de acordo com Brasil (1992).

Na casa de vegetação, após os períodos de contato, as sementes foram distribuídas em sulco no solo a $4 \mathrm{~cm}$ de profundidade, juntamente com o fertilizante,
Quadro 2. Retenção de partículas em diferentes peneiras dos fertilizantes uréia (Uréia), sulfato de amônio (SA), cloreto de potássio ( $\mathrm{KCl}$ ), sulfato de potássio $\left(\mathrm{K}_{2} \mathrm{SO}_{4}\right)$, superfosfato simples (SS), superfosfato triplo (ST) e fórmula N-P-K em grânulos e farelado, antes da instalação do experimento

\begin{tabular}{|c|c|c|c|}
\hline \multirow{2}{*}{ Fertilizante } & \multicolumn{3}{|c|}{ Retenção em malha } \\
\hline & $0,5 \mathrm{~mm}$ & $2,8 \mathrm{~mm}$ & $4 \mathrm{~mm}$ \\
\hline & $\ldots$ & $-\%$ & - \\
\hline Uréia & 0,5 & 99,5 & 0 \\
\hline $\mathrm{KCl}$ & 0,9 & 97,7 & 1,4 \\
\hline $\mathrm{SFT}$ & 1,2 & 98,2 & 0,6 \\
\hline Grânulos & 0,2 & 98,4 & 1,5 \\
\hline \multirow[t]{2}{*}{ Farelado } & 32,8 & 67,2 & 0 \\
\hline & $0,3 \mathrm{~mm}$ & $0,5 \mathrm{~mm}$ & $2 \mathrm{~mm}$ \\
\hline $\mathrm{SA}$ & 1,3 & 89,2 & 9,6 \\
\hline $\mathrm{K}_{2} \mathrm{SO}_{4}$ & 17,1 & 82,2 & 0,7 \\
\hline SS & 56,1 & 25,5 & 18,4 \\
\hline
\end{tabular}

em caixas retangulares de $5 \mathrm{~L}$ com $28 \mathrm{~cm}$ de comprimento, simulando-se uma condição prática. $\mathrm{O}$ solo utilizado nas caixas foi um Latossolo Vermelho distrófico típico textura média, passado em peneira de $4 \mathrm{~mm}$, cuja análise química, segundo métodos descritos por Raij et al. (2001), mostrou os seguintes atributos: $\mathrm{pH}\left(\mathrm{CaCl}_{2}\right), 5,0 ; \mathrm{MO}, 26 \mathrm{~g} \mathrm{dm}^{-3} ; \mathrm{H}+\mathrm{Al}$, $46 \mathrm{mmol}_{\mathrm{c}} \mathrm{dm}^{-3}$; $\mathrm{P}$ (resina), $20 \mathrm{mg} \mathrm{dm}{ }^{-3} ; 4,6,35,9 \mathrm{e}$ $14,4 \mathrm{mmolc} \mathrm{dm}^{-3} \mathrm{de} \mathrm{K}^{+}, \mathrm{Ca}^{2+} \mathrm{e} \mathrm{Mg}^{2+}$, respectivamente; CTC pH 7,0 de 100,6 mmol $_{\mathrm{c}} \mathrm{dm}^{-3}$; e V de $55 \%$, sendo o solo umedecido próximo a $70 \%$ da capacidade de campo, por meio de pesagens diárias. Foram realizadas avaliações de emergência a campo aos sete e aos 28 dias da semeadura.

Quadro 1. Valores de pH $\left(\mathrm{H}_{2} \mathrm{O}\right)$ e de condutividade elétrica $(\mathrm{CE})$ da água $\left(\mathrm{H}_{2} \mathrm{O}\right)$ e dos fertilizantes uréia (Uréia), sulfato de amônio (SA), cloreto de potássio $(\mathrm{KCl})$, sulfato de potássio $\left(\mathrm{K}_{2} \mathrm{SO}_{4}\right)$, superfosfato simples (SS), superfosfato triplo (ST) e fórmula N-P-K em grânulos e farelado

\begin{tabular}{|c|c|c|c|c|c|c|c|c|c|}
\hline & \multirow{2}{*}{$\mathrm{H}_{2} \mathrm{O}$} & \multirow{2}{*}{ Uréia } & \multirow{2}{*}{ SA } & \multirow{2}{*}{$\mathrm{KCl}$} & \multirow{2}{*}{$\mathrm{K}_{2} \mathrm{SO}_{4}$} & \multirow{2}{*}{ SFS } & \multirow{2}{*}{ SFT } & \multicolumn{2}{|c|}{ Fórmula N-P-K } \\
\hline & & & & & & & & Grânulos & Farelado \\
\hline $\mathrm{pH}^{(1)}$ & 5,7 & 5,7 & 5,2 & 5,5 & 5,9 & 4,1 & 5,2 & 4,4 & 4,8 \\
\hline Condutividade & & & & & & & & & \\
\hline elétrica $^{(1)}\left(\mu \mathrm{S} \mathrm{cm}^{-3}\right)$ & 1,97 & 3,2 & 2.060 & 1.964 & 1.416 & 290 & 1.059 & 996 & 891 \\
\hline
\end{tabular}

\footnotetext{
${ }^{(1)}$ Proporção de $1 \mathrm{~g}$ de fertilizante para 1 litro de água.
} 
Os dados foram submetidos à análise de variância para o fator fertilizante, com comparação de médias pelo teste t a $5 \%$, enquanto para o fator período de contato realizou-se análise de regressão polinomial, sendo selecionadas as regressões com maior coeficiente de determinação $\left(R^{2}\right)$, dentre as significativas pelo teste $F$.

\section{RESULTADOS E DISCUSSÃO}

A germinação de sementes de Brachiaria brizantha em laboratório e no solo foi influenciada pela interação dos fatores fertilizantes e períodos de contato (Quadro 3). Para as fontes nitrogenadas, constataram-se, em condições de laboratório, decréscimos lineares na germinação com o aumento do período de contato, reduzindo em 25 e 57 \% após $96 \mathrm{~h}$ de contato com o fertilizante, quando da utilização de uréia e sulfato de amônio, respectivamente (Figura 1a). No solo, verificou-se efeito quadrático, visto que ambas as fontes proporcionaram aumento da germinação até o período de 57 e $52 \mathrm{~h}$ para a uréia e o sulfato de amônio, respectivamente (Figura 1b).

Quadro 3. Resultado de análise estatística da germinação em laboratório e emergência no solo de sementes de Brachiaria brizantha em razão de fertilizantes e períodos de contato com diferentes fertilizantes

\begin{tabular}{|c|c|c|}
\hline Fator & Germinação & Emergência no solo \\
\hline Fertilizante & + & $\%$ \\
\hline Uréia & $49,7 \mathrm{bc}$ & $24,3 \mathrm{c}$ \\
\hline Sulfato de amônio & $43,7 \mathrm{~d}$ & $37,2 \mathrm{ab}$ \\
\hline Cloreto de potássio & $52,8 \mathrm{ab}$ & $37,2 \mathrm{ab}$ \\
\hline Sulfato de potássio & $50,3 \mathrm{abc}$ & $35,9 \mathrm{ab}$ \\
\hline Superfosfato simples & $47,5 \mathrm{~cd}$ & $38,4 \mathrm{a}$ \\
\hline Superfosfato triplo & $49,8 \mathrm{bc}$ & $34,5 \mathrm{~b}$ \\
\hline Formulado farelado & $51,5 \mathrm{ab}$ & $35,6 a b$ \\
\hline Formulado granulado & 53,9 a & 38,9 a \\
\hline \multicolumn{3}{|l|}{ Período(1) } \\
\hline 0 hora & 56,6 & 33,83 \\
\hline 6 horas & 55,1 & 34,84 \\
\hline 12 horas & 54,6 & 34,76 \\
\hline 24 horas & 47,1 & 39,01 \\
\hline 48 horas & 43,0 & 37,75 \\
\hline \multirow[t]{2}{*}{96 horas } & 43,0 & 37,11 \\
\hline & \multicolumn{2}{|c|}{ Valor de F } \\
\hline Fertilizantes (F) & $5,21 * *$ & $14,22^{* *}$ \\
\hline Período $(\mathrm{P})$ & $26,70 * *$ & $2,31^{*}$ \\
\hline $\mathrm{F} \times \mathrm{P}$ & $5,46^{* *}$ & $2,70 * *$ \\
\hline $\mathrm{CV}(\%)$ & 13,80 & 17,23 \\
\hline
\end{tabular}

Médias seguidas de mesma letra não diferem entre si pelo teste de t a $5 \%$. ${ }^{* *}$, * e ns, significativo a 1 e $5 \%$ e não-significativo, respectivamente.

${ }^{(1)}$ Médias para todos os fertilizantes.

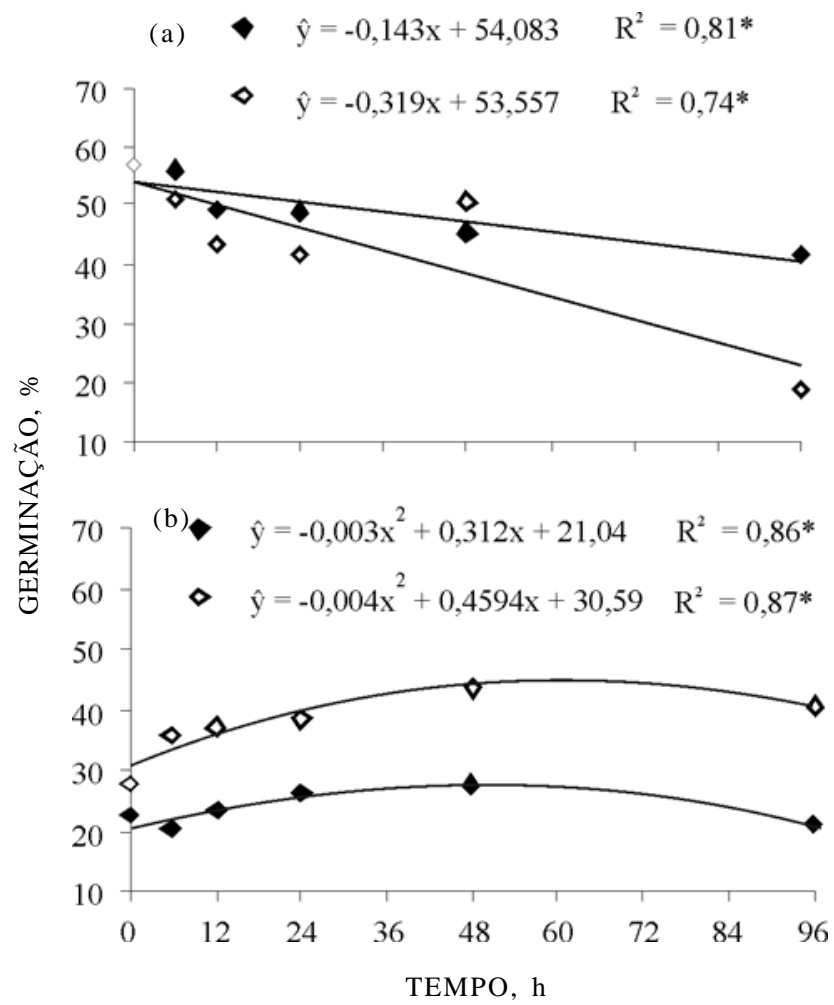

Figura 1. Germinação de sementes de Brachiaria brizantha em razão do período de contato com uréia $(\diamond)$ e sulfato de amônio $(\diamond)$, em condições de laboratório (a) e no solo (b).

Nota-se comportamento distinto do efeito dos adubos nitrogenados em condições de laboratório e no solo, em casa de vegetação. Deve-se ressaltar, no entanto, que no caso do laboratório, após a separação da semente misturada ao adubo, esta foi colocada em papel-toalha e mantida em umidade de $100 \%$. Nessas condições, o efeito salino, ou mesmo de $\mathrm{pH}$, das partículas de fertilizantes que permaneceram sobre a semente, tanto pelo seu tamanho ou mesmo por já haver solubilizado devido à umidade do ar, atuou negativamente sobre a germinação, seja inibindo-a ou promovendo morte de plântulas recém-germinadas. De acordo com Carvalho \& Nakagawa (2000), o estádio de maior sensibilidade das plantas à variação da salinidade (CE) e do pH é justamente após a germinação; contudo, elevada concentração salina pode também afetar a hidratação e absorção de água, sendo estes os processos iniciais da germinação.

A diferença observada no laboratório entre as fontes uréia e sulfato de amônio pode ser explicada pelo fato de a salinidade do sulfato de amônio ser muitas vezes superior à da uréia, que, antes de ser hidrolisada, praticamente não tem efeito sobre a CE. Deve-se considerar também que a uréia necessita de urease para se hidrolizar, enzima esta que deve ser escassa nessas condições (Mello, 1987). Outra hipótese, porém de menor plausibilidade, é de que o sulfato de amônio 
apresenta menor $\mathrm{pH}$ inicial em relação à uréia, apesar da pequena diferença na proporção estudada (Quadro 1), podendo também esse fato ter influenciado a germinação.

Quando se avalia a germinação no solo, deve-se considerar que, de modo geral, os valores são mais baixos em relação aos do laboratório. Pode-se sugerir que o fato de os adubos serem aplicados junto à semente tenha promovido esse efeito. Apesar de os resultados apresentarem uma equação e um ponto de máximo (48 h) como o de maior germinação, a variação entre o maior e o menor ponto é inferior a $10 \%$.

Diferentemente do que aconteceu no laboratório, no solo houve a semeadura das sementes misturadas aos fertilizantes; nesse substrato, pode ter ocorrido efeito-tampão da concentração salina, reduzindo os efeitos deletérios à germinação.

De forma semelhante, pode-se avaliar a germinação das sementes nas fontes de P (SS e ST). O tempo de contato do SS e ST teve efeito quadrático, com diminuição da germinação em laboratório até 48 h, e não influenciou a germinação no solo (Figura 2a, b). Deve-se considerar, no entanto, que as fontes fosfatadas têm menor efeito na CE, comparadas ao SA. Os fertilizantes fosfatados são obtidos pelo processamento da rocha fosfatada com o uso de ácidos sulfúrico (SS) e fosfórico (ST), deixando

(a)

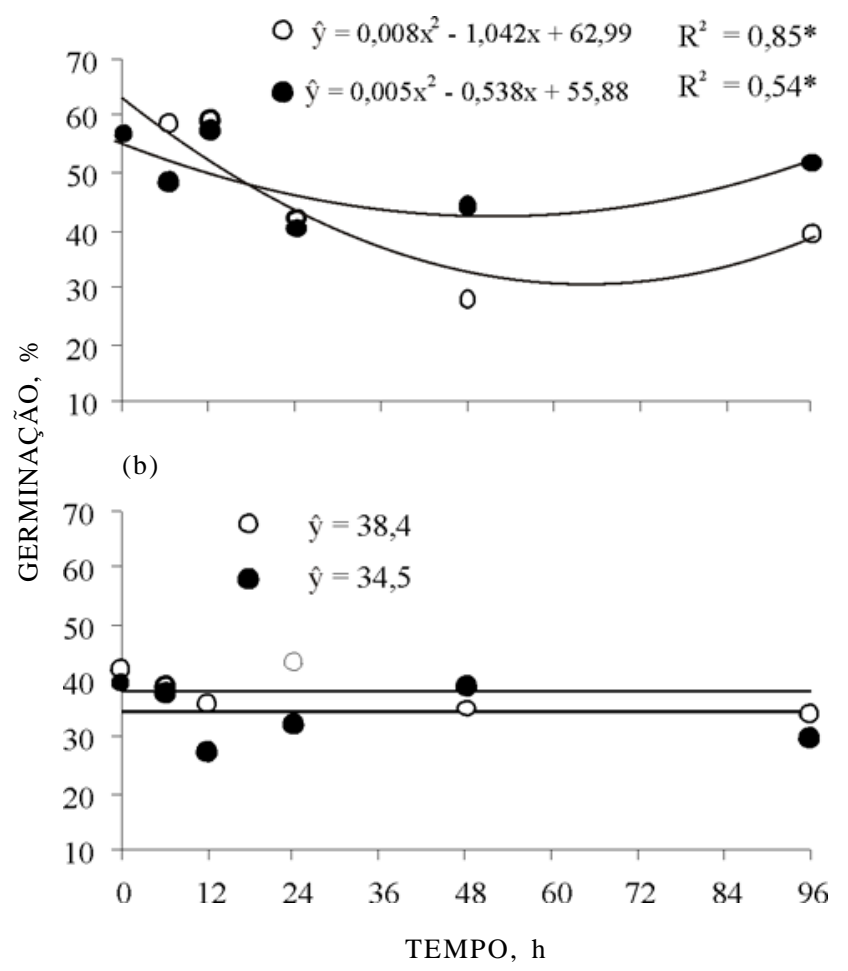

Figura 2. Germinação de sementes de Brachiaria brizantha em razão do período de contato com superfosfato simples (๑) e superfosfato triplo (o), em condições de laboratório (a) e no solo (b). resíduos capazes de influenciar negativamente a germinação e o vigor das sementes, quando em mistura com os fertilizantes, sendo esse efeito acentuado com o período de contato (Lima et al., 2000; Soratto et al., 2004).

Comparando as fontes de $\mathrm{K}\left(\mathrm{KCl}\right.$ e $\left.\mathrm{K}_{2} \mathrm{SO}_{4}\right)$, em condições de laboratório, nota-se que o $\mathrm{KCl}$ reduziu a germinação das sementes, diminuindo de forma quadrática ao período de contato, enquanto o sulfato de potássio não influenciou a germinação (Figura 3a). No solo, o sulfato de potássio apresentou comportamento inverso, uma vez que ocasionou $33 \%$ de incremento da germinação à medida que aumentou o tempo de contato (efeito linear); para o cloreto de potássio, tal efeito não foi constatado (Figura 3b).

O efeito salino na germinação ocorre quando a concentração de sais da solução for maior que a da semente (Desai et al., 2004). Deve-se considerar que a condutividade elétrica dos adubos foi determinada com a mistura de $1 \mathrm{~g}$ de fertilizante por $1 \mathrm{~L}$ de água, porém, no germinador, com umidade relativa elevada, forma-se uma película de água, que é suficiente para solubilizar o adubo, fazendo com que a CE dessa solução seja muito mais elevada que a observada no quadro 1. Assim, o efeito verificado em condições de laboratório, para o $\mathrm{KCl}$, pode ser atribuído à concentração salina, que, juntamente com o SA, apresentaram os maiores valores.

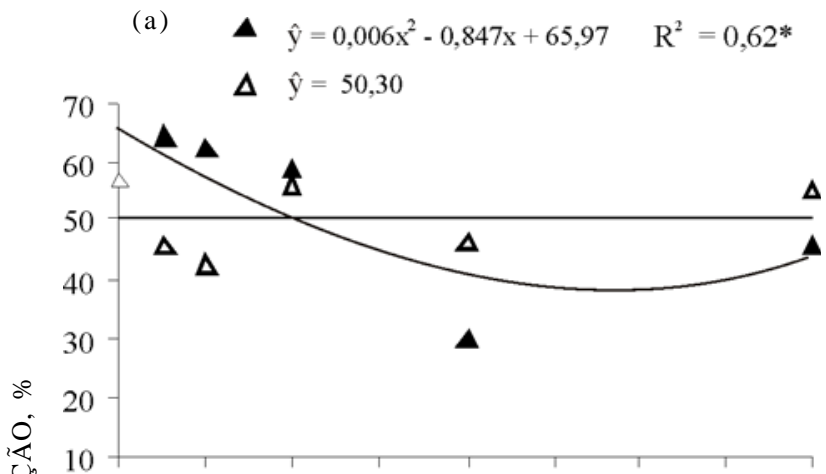

(b)

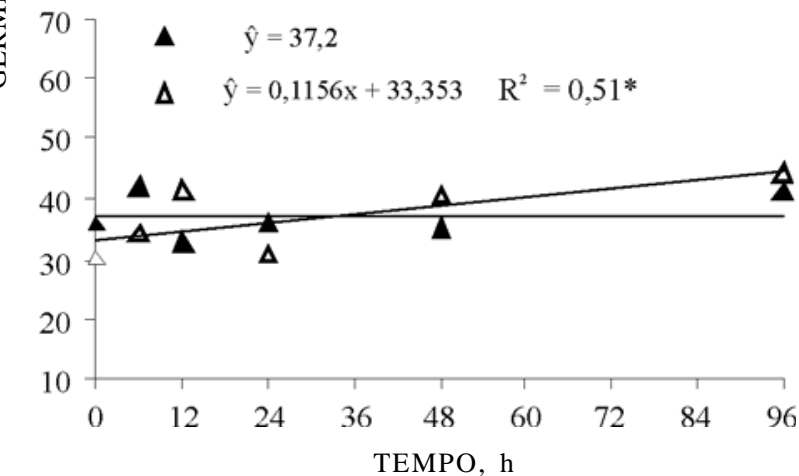

Figura 3. Germinação de sementes de Brachiaria brizantha em razão do período de contato com cloreto de potássio $(\triangle)$ e sulfato de potássio $(\Delta)$, em condições de laboratório (a) e no solo (b). 
Quando utilizada a fórmula 8-28-16 em formas físicas diferentes (granulada e farelada), nota-se que o formulado farelado reduziu linearmente a germinação em laboratório, chegando a $34 \%$ após $96 \mathrm{~h}$. Tal efeito não foi constatado ao misturar as sementes com o formulado granulado (Figura 4a). Esse efeito diferenciado entre os formulados deve-se à granulometria, uma vez que o granulado tem partículas maiores que o farelado (Quadro 2), tendo como conseqüência menor contato adubo e semente.

Comportamento contrário foi observado para germinação no solo, onde houve aumento quando foi usado fertilizante granulado; para o farelado, isso não ocorreu (Figura 4b). Entretanto, a maior diferença na emergência de plântulas foi de apenas $17 \%$ no maior período de contato.

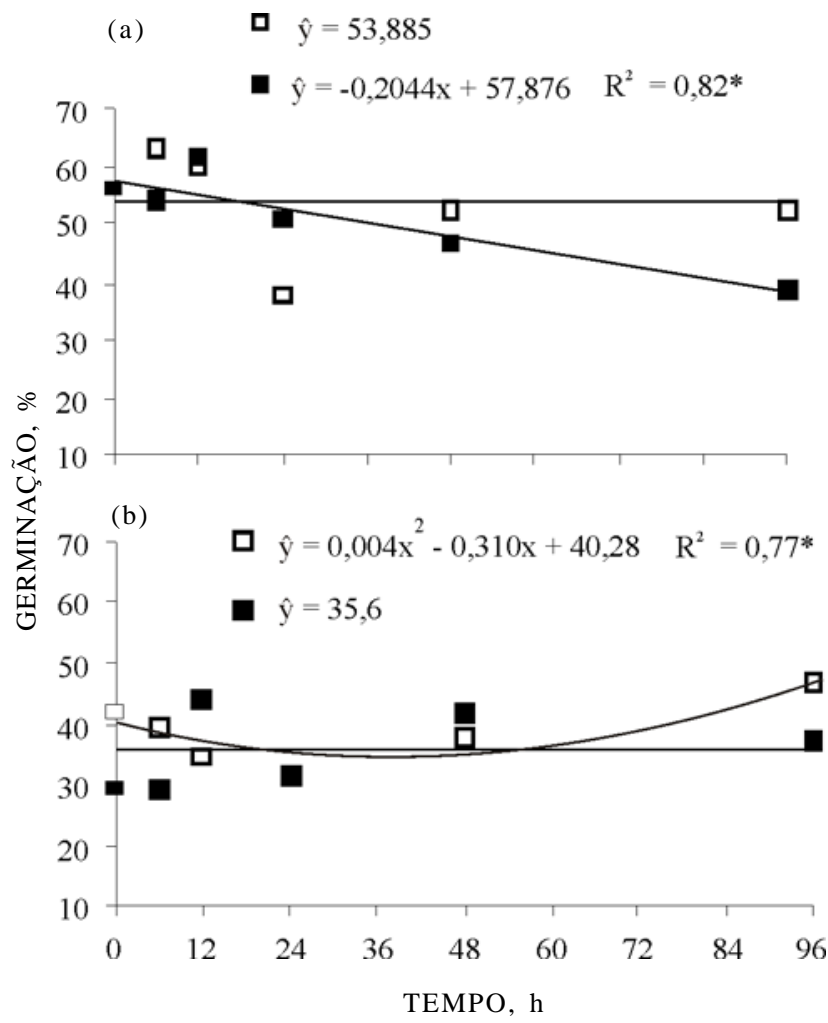

Figura 4. Germinação de sementes de Brachiaria brizantha em razão do período de contato com formulado granulado ( $\square$ ) e formulado farelado (ם), em condições de laboratório (a) e no solo (b).

\section{CONCLUSÕES}

1. Não houve relação entre os testes de germinação em laboratório e no solo.

2. No solo, a emergência das plântulas de Brachiaria brizantha não é afetada se a mistura com fertilizantes minerais fosfatados, cloreto de potássio e formulado farelado for realizada até $96 \mathrm{~h}$ antes da semeadura.

\section{LITERATURA CITADA}

AIDAR, H.; RODRIGUES, J.A.S. \& KLUTHCOUSKI, J. Uso da integração lavoura-pecuária para produção de forragem na entressafra. In: KLUTHCOUSKI, J.; STONE, L.F. \& AIDAR, H. Integração Lavoura-Pecuária. Santo Antonio de Goiás, Embrapa Arroz e Feijão, 2003. p.225-262.

BACCHI, O. Mistura de sementes de colonião com superfosfato (Panicum maximum Jacq.). R. Bras. Sementes, falta volume 38-40, 1974.

BRASIL. Ministério da Agricultura. Brasília: Regras para análise de sementes. Brasília, SNAD, DNPV, CLAV, 1992. 365 .

CARVALHO, N.M. \& NAKAGAWA, J., eds. Sementes: ciência, tecnologia e produção. 4.ed. Jaboticabal, Funep, 2000. 588p.

CAVARIANI, C.; NAKAGAWA, J. \& VELINI, E.D. Mistura de fertilizantes fosfatados com sementes de Brachiaria decumbens Stapf e Brachiaria brizantha (Hochst Ex A. Rich) Stapf. R. Bras. Sementes, 16:163-167, 1994.

DESAI, B.B.; KOTECHA, P.M. \& SALUNKE, D.K. Seeds handbook: biology, production, processing and storage. 2.ed. New York, Marcel Dekker, 2004. 787p.

JAKELAITIS, A.; SILVA, A.A.; FERREIRA, L.R.; SILVA, A.F. \& FREITAS, F.C.L. Manejo de plantas daninhas no consórcio de milho com capim-braquiária (Brachiaria decumbens). Planta Daninha, 22:553-560, 2004.

KLUTHCOUSKI, J.; COBUCCI, T.; AIDAR, H.; YOKOYAMA, L.P.; OLIVEIRA, I.P. ;COSTA, J.L.S.; SILVA, J.G.; VILELA, L.; BACELLOS, A.O. \& MAGNABOSCO, C.U. Sistema Santa Fé - Tecnologia Embrapa: integração lavoura-pecuária pelo consórcio de culturas anuais com forrageiras, em áreas de lavoura, nos sistemas direto e convencional. Santo Antonio de Goiás, Embrapa Arroz e Feijão, 2000. 28p. (Circular Técnica, 38)

KLUTHCOUSKI, J.; STONE, L.F.\& AIDAR, H. Integração Lavoura-Pecuária. Santo Antonio de Goiás, Embrapa Arroz e Feijão, 2003. 570p.

LIMA, E.V.; CAVARIANI, C.; LIMA, P.L.; CRUSCIOL, C.A.C.; NAKAGAWA, J. \& VILLAS BOAS, R.L. Qualidade fisiológica de sementes de painço (Panicum dichotomiflorum Mix.) em função do tempo de mistura com o superfosfato triplo. Cult. Agron., 9:177-189, 2000.

MELLO, F.A.F. Uréia fertilizante. Campinas, Fundação Cargill, 1987. 192p.

MOURA, J.C. Manejo e adubação de pastagens. Piracicaba, Instituto de Potassa e Fosfato, 1984. 12p. (Informações Agronômicas, 25)

PORTES, T.A.; CARVALHO, S.I.C.; OLIVEIRA, I.P. \& KLUTHCOUSKI, J. Análise do crescimento de uma cultivar de braquiária em cultivo solteiro e consorciado com cereais. Pesq. Agropec. Bras., 35:1349-1358, 2000.

RAIJ, B.van.; ANDRADE, J.C.; CANTARELLA, H. \& QUAGGIO, J.A. Análise química para avaliação da fertilidade de solos tropicais. Campinas, Instituto Agronômico, 2001. 285p.

ROSTON, A.J. \& KUHN NETO, J. Método CATI de formação de pastagens. 2.ed. Campinas, CATI, 1978. 8p. (Instrução Prática, 191) 
SADER, R.; GAVIOLI, E.A.; MATTOS Jr., D.; PEREIRA, C.P. \& MELLO, F.A.A. Efeito da mistura de fertilizantes fosfatados na germinação de sementes de Brachiaria brizantha (Hochst Ex A. Rich) Stapf e de Brachiaria decumbens Stapf. R. Bras. Sementes, 13:37-43, 1991.

SALTON, J.C.; FABRÍCIO, A. M.\& HERNANI, L. C. Integração lavoura-pecuária: alternativas de rotação de culturas. In: ENCONTRO REGIONAL DE PLANTIO DIRETO NO CERRADO, 5., Dourados, 2001. Anais. Dourados, UFMS/ Embrapa-CNPAO, 2001. p.31-32 (Documentos, 31)
SÃO PAULO. Secretaria da Agricultura. Normas para manejo de pastagens. Campinas, CATI, 1973. 41p.

SILVA, A.C.; FERREIRA, L.R.; SILVA, A.A.; PAIVA, T.W. B. \& SEDIYAMA, C.S. Efeitos de doses reduzidas de fluazifop - p - butil no consórcio entre soja e Brachiaria brizantha. Planta Daninha, 22:429-435, 2004.

SORATTO, R.P.; LIMA, E.V.; MAUAD, M.; BOAS, R.L. V. \& NAKAGAWA, J. Millet seeds mixed with phosphate fertilizers. Sci. Agric., 60:573-579, 2003. 